\title{
Twenty-four-Hour Osteocalcin, Carboxyterminal Propeptide of Type I Procollagen, and Aminoterminal Propeptide of Type III Procollagen Rhythms in Normal and Growth-Retarded Children
}

\author{
G. SAGGESE, G. I. BARONCELli, S. BERTELlONI, L. CINQUANTA, AND G. DiNERO
}

Department of Pediatrics, University of Pisa, Pisa. Italy

\begin{abstract}
The relationships between spontaneous variations in serum 24-h osteocalcin (OC), carboxyterminal propeptide of type I procollagen (PICP), and aminoterminal propeptide of type III procollagen (PIIINP) concentrations and $\mathrm{GH}$ secretion, measured as $\mathrm{GH}$ response to provocative pharmacologic stimuli and spontaneous $\mathbf{G H}$ secretion during $24 \mathrm{~h}$, were evaluated in prepubertal normal children and in GH-deficient and GH-secreting short normal children (SNC). All the subjects showed a circadian rhythm in smoothed 24-h OC and PICP mean data with higher nocturnal values in comparison with diurnal values. Conversely, serum PIIINP concentrations did not vary throughout the day. In children with classic GH deficiency and nonclassic GH deficiency, mean 24-h serum levels and smoothed 24-h mean data for OC, PICP, and PIIINP were significantly reduced $(p<0.001)$ with respect to agematched controls. SNC showed mean 24-h OC concentrations similar $(p=N S)$ to those we found in age-matched controls, but they had significantly lower $(p<0.001)$ diurnal 12-h mean data in comparison with controls. SNC also showed both 24-h PICP and PIIINP mean data and smoothed 24-h PICP and PIIINP mean data significantly lower (from $p<0.02$ to $p<0.001$ ) at all the time points of measurement in comparison with controls. Twenty-fourhour PICP and PIIINP mean data were positively related to spontaneous 24-h GH concentrations $(r=0.77, p<$ 0.005 and $r=0.69, p<0.005$, respectively) and growth velocity $(r=0.85, p<0.005$, and $r=0.70, p<0.005$, respectively), whereas 24-h OC mean data were not. Our study suggests that circadian serum PICP and PIIINP concentrations show $\mathrm{GH}$ dependency in children with classic GH deficiency and those with nonclassic GH deficiency, but this was less evident in SNC. Serum PICP and PIIINP concentrations may reflect somatic growth in children with short stature that is or is not related to $\mathbf{G H}$ deficiency. (Pediatr Res 35: 409-415, 1994)
\end{abstract}

\section{Abbreviations}

PIIINP, aminoterminal propeptide of type III procollagen PICP, carboxyterminal propeptide of type I procollagen

GH, growth hormone

CGHD, classic GH deficiency

MGHC, mean GH concentration

NCGHD, nonclassic GH deficiency

Received June 22. 1993; accepted November 30, 1993.

Correspondence: Giuseppe Saggese, M.D.. Endocrine Unit, Chair of Preventive Pediatrics, Department of Pediatrics, University of Pisa, Via Roma, 65, I-56125 Pisa, Italy.
OC, osteocalcin

SNC, short normal children

Some biochemical markers to evaluate bone metabolism and growth-related changes have been proposed. Of these, $\mathrm{OC}$ and type I and type III procollagen propeptides seem to be promising for application in clinical practice.

OC, or bone $\gamma$-carboxyglutamic acid (Gla) protein, is a major noncollagenous protein of the bone matrix specifically secreted by osteoblasts; a small fraction, less than $1 \%$, is released into circulation, where it is measurable by RIA (1). Although physiologic functions of $\mathrm{OC}$ are still unknown, circulatory levels of this bone protein may represent a marker of bone formation, OC values being higher at ages when the bone mineralization rate is increased $(2,3)$.

Interstitial collagens are the major structural proteins of the extracellular matrix. Type I collagen is the most abundant body collagen and is a major product of osteoblasts, accounting for more than $90 \%$ of the organic bone matrix $(4,5)$. The same gene product also occurs in soft connective tissues, where type I collagen is present with a mixture of other collagens (5). Type III collagen is mainly located in soft connective tissues and is a major component of interstitial fibrils (6). Type I and type III collagens are derived from specific precursor molecules called procollagens, which are synthesized intracellularly. During the synthesis, large, soluble propeptide domains are released into the circulation from the precursor molecules (6); sensitive, reproducible, and specific RIA for PICP (7) and PIIINP (8) are now commercially available to measure circulatory levels of both propeptides. Serum PICP concentration seems to reflect osteoblast activity and could serve as an index of bone and linear growth (4, 9-11), whereas serum PIIINP concentration seems to reflect only somatic growth $(8,9,11)$.

During childhood, serum levels of OC, PICP, and PIIINP change in relation to chronologic age with patterns resembling growth velocity curves $(2,8,12,13)$. In GH-deficient children, low baseline serum OC (14-18), PICP $(11,17,19)$, and PIIINP $(8,11,20)$ concentrations have been reported, and a positive correlation between serum $\operatorname{OC}(15,16,18), \operatorname{PICP}(11,17)$, and $\operatorname{PIIINP}(8,11,20,21)$ concentrations and growth velocity during $\mathrm{GH}$ treatment has been found. In SNC, normal (22) or reduced (23) baseline serum OC levels have been observed. Trivedi $e t$ al. (11) found that SNC tended to have somewhat higher baseline serum PICP values than healthy children, whereas they had reduced baseline serum PIIINP concentrations $(8,11,20)$.

In healthy young adults and prepubertal children, variations 
in serum OC levels during a 24-h period have been observed (24-27); serum OC concentrations show considerable time point variability and nocturnal values are $20-50 \%$ higher than diurnal values (24-26). In GH-deficient children (28) as well as in SNC $(29,30)$, an abnormal pattern in serum OC values has been reported. Although some investigators did not find circadian PICP variation in healthy subjects ranging in age from 30 to 68 y (31), others (32) showed a significant PICP circadian rhythm with about $20 \%$ higher values at night than in the afternoon in premenopausal women. To our knowledge, no data are available for children. No apparent PIIINP circadian rhythm was discerned in children with GH deficiency (8) or idiopathic short stature (33).

In this study, we evaluated 24-h OC, PICP, and PIIINP variations in healthy, prepubertal, normal-statured children; in GHdeficient children; and in SNC to assess 1 ) whether 24-h spontaneous GH secretion affects the circadian concentrations of these biochemical markers and 2) the relationships among 24-h variations in serum OC, PICP, and PIIINP concentrations and growth.

\section{MATERIALS AND METHODS}

Patients. Forty prepubertal children (22 males, 18 females) aged 4.1-9.5 y were examined. All children had normal weight and length at birth, had normal renal, liver, and gastrointestinal function, and did not take drugs known to interfere with bone or mineral metabolism or collagen synthesis. Vitamin D status was normal in all the subjects (25-hydroxyvitamin D serum levels more than $45 \mathrm{nmol} / \mathrm{L}$ ). Karyotype, examined in all females, was $46, \mathrm{XX}$. By using diagnostic criteria previously described (34), we subdivided 34 untreated patients with short stature into three groups: group A consisted of nine children with isolated CGHD, group B consisted of 13 children with isolated NCGHD, and group C consisted of 12 SNC. Diagnosis was made on the basis of the auxologic findings (Table 1) and biochemical data. Patients in group A had $\mathrm{GH}$ peaks $<10 \mu \mathrm{g} / \mathrm{L}$ after two provocative pharmacologic stimuli (levodopa: $500 \mathrm{mg} / 1.73 \mathrm{~m}^{2}$ and insulin tolerance test: $0.1 \mathrm{IU} / \mathrm{kg}$ of regular insulin i.v.) and reduced spontaneous MGHC for $24 \mathrm{~h}(<3 \mu \mathrm{g} / \mathrm{L})$ (34) (Fig. 1). Patients in group B had similar auxologic findings but normal $\mathrm{GH}$ response (peaks $>10 \mu \mathrm{g} / \mathrm{L}$ ) to at least one provocative pharmacologic stimulus (levodopa or insulin tolerance test) and reduced MGHC $(<3 \mu \mathrm{g} / \mathrm{L}$ ) (Fig. 1). Patients in group $\mathrm{C}$ were healthy, slowly growing short children: all were less than the 3rd percentile in height and growing at less than the 25 th percentile for chronologic age (Table 1). They showed normal GH response (peaks $>10 \mu \mathrm{g} / \mathrm{L}$ ) to at least one provocative pharmacologic stimulus (levodopa or insulin tolerance test) and normal MGHC $(>3 \mu \mathrm{g} / \mathrm{L}$ ) (Fig. 1). The control group consisted of six prepubertal, normal-statured, healthy children, siblings of the patients in group $\mathrm{A}(n=2,1$ male and 1 female), group $\mathrm{B}(n=3,1$ male

Table 1. Auxologic findings of subjects*

\begin{tabular}{lcccc}
\hline & CGHD & NCGHD & SNC & Controls \\
\hline$n$ & 9 & 13 & 12 & 6 \\
Gender & $5 \mathrm{M} / 4 \mathrm{~F}$ & $7 \mathrm{M} / 6 \mathrm{~F}$ & $7 \mathrm{M} / 5 \mathrm{~F}$ & $3 \mathrm{M} / 3 \mathrm{~F}$ \\
Chronologic age & $6.8 \pm 1.9$ & $7.0 \pm 2.2$ & $6.0 \pm 1.9$ & $6.9 \pm 1.7$ \\
$\quad(y)$ & & & & \\
Bone age (y) & $4.2 \pm 1.3$ & $4.9 \pm 1.6$ & $5.2 \pm 2.1$ & $6.4 \pm 1.8$ \\
Statural age (y) & $4.0 \pm 1.5$ & $4.6 \pm 1.7$ & $4.3 \pm 1.9$ & $6.8 \pm 1.6$ \\
Bone age/chrono- & 0.62 & 0.65 & 0.82 & 0.93 \\
$\quad$ logic age ratio & & & & \\
Height $z$ score & $-3.2 \pm 0.6$ & $-3.1 \pm 0.8$ & $-2.3 \pm 1.2$ & $-0.2 \pm 0.2$ \\
Growth velocity & $2.8 \pm 0.6$ & $2.9 \pm 0.7$ & $4.4 \pm 0.3$ & $5.8 \pm 0.6$ \\
$\quad$ (cm/y) & & & & \\
Growth velocity & $-3.4 \pm 0.7$ & $-3.2 \pm 0.7$ & $-1.8 \pm 0.2$ & $-0.3 \pm 0.3$ \\
$\quad z$ score & & & & \\
\hline
\end{tabular}

*Values are mean $\pm \mathrm{SD}$. and 2 females), and group $C(n=1$, male) (Table 1). All these children had normal $\mathrm{GH}$ response (peaks $>10 \mu \mathrm{g} / \mathrm{L}$ ) after two provocative pharmacologic stimuli (levodopa and insulin tolerance test) and normal MGHC (>3 $\mu \mathrm{g} / \mathrm{L})$ (Fig. 1). There were no differences in baseline serum concentrations of ionized calcium, phosphate, magnesium, intact PTH, and 1,25-dihydroxyvitamin $\mathrm{D}$, or in circadian rhythm in serum cortisol and thyroid hormones, between patients and controls (data not shown).

Study design. During pharmacologic stimulation, blood samples for GH measurements were drawn every $20 \mathrm{~min}$ for $2 \mathrm{~h}$ in both tests. Hypoglycemia was achieved in all subjects (patients and controls) during the insulin tolerance test. To evaluate spontaneous GH secretion, we drew samples from each child every $20 \mathrm{~min}$ for $24 \mathrm{~h}$ (from 0800 to 0800 of the following day), and all 73 samples for each child were measured (34).

In all children, we also collected samples to evaluate spontaneous 24-h variations in serum OC, PICP, and PIIINP at the same time point at which $\mathrm{GH}$ concentrations were measured. All subjects were adapted to the study room for $12 \mathrm{~h}$ overnight. Blood was sampled through an indwelling venous catheter $(\mathrm{Ab}$ bocath T-22G, Abbott, Campoverde, Latina, Italy) placed in the antecubital vein in each subject at least $8 \mathrm{~h}$ before the test. Samples for GH, OC, PICP, and PIIINP were stored at $-20^{\circ} \mathrm{C}$ within 30 min of being drawn until analyzed. Meals were given at $0800,1200,1600$, and $2000 \mathrm{~h}$ with calcium and phosphorus intake adequate for age and sex; physical activity was restricted and standardized during daytime within our department. All subjects were investigated from November to February. In three CGHD children, four NCGHD children, and two SNC, OC, GH, PICP, and PIIINP circadian variations were reevaluated during March and April.

Informed consent was obtained from the parents of each child, and the study was approved by the ethical committee for human investigation of our department.

Methods. To allow a comparison between different ages and genders, we expressed height as a $z$ score with respect to height SD according to the method of Tanner et al. (35). Growth velocity was expressed as $\mathrm{cm} / \mathrm{y}$ and as $z$ score with respect to growth velocity SD by using Tanner tables (35). Standing height was measured with a wall-mounted stadiometer. Bone age was evaluated by using the Greulich and Pyle method (36).

All the examined biochemical parameters were detected by RIA using the following commercial kits: GH Spectria (Farmos Diagnostica, Turku, Finland); OC (Incstar Co., Stillwater, MN); and CPP-I and APP-III (Farmos Diagnostica). For GH, interassay and intraassay coefficients of variation and sensitivity were $7.8 \%, 5.1 \%$, and $0.3 \mu \mathrm{g} / \mathrm{L}$, respectively; for $\mathrm{OC}, 8.9 \%, 6.3 \%$, and $0.2 \mu \mathrm{g} / \mathrm{L}$; for PICP, $4.7 \%, 3.5 \%$, and $1.2 \mu \mathrm{g} / \mathrm{L}$; and for PIIINP, $6.5 \%, 5.2 \%$, and $0.2 \mu \mathrm{g} / \mathrm{L}$.

Statistical analysis. We considered the value of $3 \mu \mathrm{g} / \mathrm{L}$ the cutoff limit between normal $(\geq 3 \mu \mathrm{g} / \mathrm{L})$ and reduced $(<3 \mu \mathrm{g} / \mathrm{L})$ spontaneous 24-h MGHC (34). For each study day, the mean 24-h values of OC, PICP, and PIIINP were obtained by calculating the average of serum concentrations of these parameters of each subject for all the time points; results are expressed as mean \pm SD and as $z$ score with respect to control subjects' SD for OC, PICP, and PIIINP by using the following formula: measured individual value - mean value for age-matched controls/SD for age-matched controls. The mean patterns of each parameter were smoothed by the method of running means (37).

We also calculated mean 12-h values of $\mathrm{GH}, \mathrm{OC}, \mathrm{PICP}$, and PIIINP for both nocturnal and diurnal periods by measuring the average of serum concentrations of these parameters of each subject for all daytime points (from $0800 \mathrm{~h}$ to $1900 \mathrm{~h}$ ) and nighttime points (from 2000 to $0700 \mathrm{~h}$ ). Data are expressed as mean $\pm S D$.

Mean values were compared by analysis of variance. Multiple regression analysis was performed to determine correlation coefficients. A $p<0.05$ was considered significant. 

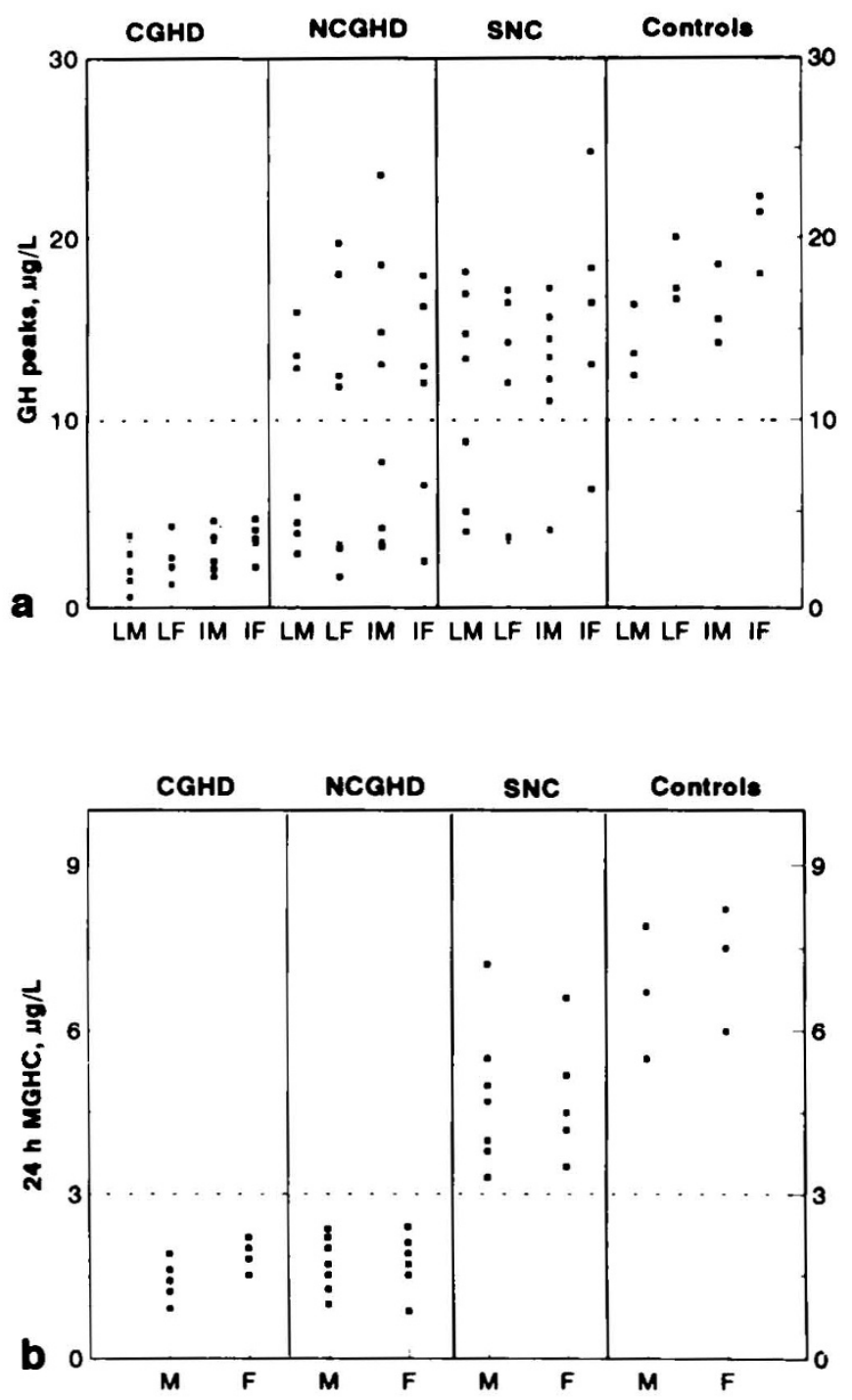

Fig. 1. $a, \mathrm{GH}$ secretion after provocative pharmacologic stimuli ( $L$, levodopa; $I$, insulin tolerance test), and $b$, spontaneous 24 -h MGHC of the subjects. Data are expressed as single value for males $(M)$ and females $(F)$. The area above the broken line indicates normal values.

\section{RESULTS}

Figure 1 summarizes the results of $\mathrm{GH}$ response to provocative pharmacologic stimuli and spontaneous 24-h MGHC in all subjects. All CGHD and NCGHD children had 24-h MGHC below the cutoff limit of $3 \mu \mathrm{g} / \mathrm{L}$ (Fig. 1), with a mean $(1.6 \pm 0.4$ $\mu \mathrm{g} / \mathrm{L}$ and $1.7 \pm 0.5 \mu \mathrm{g} / \mathrm{L}$, respectively) significantly reduced $(p$ $<0.001)$ in comparison with that of SNC $(4.8 \pm 1.1 \mu \mathrm{g} / \mathrm{L})$ and controls $(7.0 \pm 1.0 \mu \mathrm{g} / \mathrm{L})$. In SNC, each individual value of 24h MGHC was more than $3 \mu \mathrm{g} / \mathrm{L}$ (Fig. 1), but the mean of all MCGH was significantly lower $(p<0.01)$ than that of controls.

In both CGHD and NCGHD children, mean serum 24-h OC $(5.2 \pm 1.4 \mu \mathrm{g} / \mathrm{L}$ and $5.5 \pm 1.3 \mu \mathrm{g} / \mathrm{L}$, respectively), PICP $(18.3 \pm$ $2.0 \mu \mathrm{g} / \mathrm{L}$ and $18.8 \pm 2.0 \mu \mathrm{g} / \mathrm{L}$, respectively), and PIIINP $(4.1 \pm$ $0.9 \mu \mathrm{g} / \mathrm{L}$ and $4.1 \pm 1.0 \mu \mathrm{g} / \mathrm{L}$, respectively) levels were significantly reduced $(p<0.001)$ in comparison with those found in controls (OC: $14.5 \pm 2.5 \mu \mathrm{g} / \mathrm{L}$, PICP: $32.4 \pm 4.6 \mu \mathrm{g} / \mathrm{L}$, and PIIINP: $7.9 \pm 1.0 \mu \mathrm{g} / \mathrm{L})$. In SNC, mean 24-h serum OC concentration $(12.2 \pm 2.1 \mu \mathrm{g} / \mathrm{L})$ was not significantly different $(p=\mathrm{NS})$ compared with that of controls, but it was significantly higher $(p$ $<0.001$ ) than that found in CGHD and NCGHD children. In SNC, mean serum 24-h PICP $(24.6 \pm 3.1 \mu \mathrm{g} / \mathrm{L})$ and PIIINP $(6.6$ $\pm 1.1 \mu \mathrm{g} / \mathrm{L})$ concentrations were significantly higher $(p<0.001)$ than those in CGHD and NCGHD children and significantly reduced $(p<0.001$ for PICP and $p<0.02$ for PIIINP) in comparison with the controls. Data expressed as $z$ score in respect to control subjects' SD are reported in Figure 2: all CGHD and NCGHD children had mean serum 24-h OC, PICP, and PIIINP values below $-2.0 z$ score, whereas SNC had mean serum 24-h OC, PICP, and PIIINP values either below $-2.0 z$ score or within the normal limit for age. However, there was a clear overlap between both CGHD and NCGHD children and SNC, and between SNC and controls for OC, PICP, and PIIINP (Fig. 2).

In all subjects, a circadian rhythm in smoothed 24-h OC and PICP mean data was found, with higher nocturnal values in comparison with diurnal values (Fig. 3). Maximal peaks of $O C$ were evident from 0000 to $0300 \mathrm{~h}$ in CGHD and NCGHD children and from 0100 to $0500 \mathrm{~h}$ in SNC and controls (Fig. 3); maximal peaks of PICP were present from 0200 to $0400 \mathrm{~h}$ in CGHD and NCGHD children, from 0300 to $0430 \mathrm{~h}$ in SNC, and from 0230 to $0430 \mathrm{~h}$ in controls (Fig. 3). Spontaneous maximal GH peaks greater than $5 \mu \mathrm{g} / \mathrm{L}$ were evident from 0000 to $0200 \mathrm{~h}$ in controls and SNC, whereas in CGHD and NCGHD children no $\mathrm{GH}$ peaks greater than $5 \mu \mathrm{g} / \mathrm{L}$ were observed throughout the 24-h period (data not shown). In all subjects, smoothed 24-h OC mean data showed greater variations during daytime than smoothed 24-h PICP mean data (Fig. 3). On the contrary, serum PIIINP levels did not vary throughout the day in any subjects (Fig. 3). When the smoothed 24-h OC, PICP, and PIIINP mean data of the CGHD and NCGHD children were 

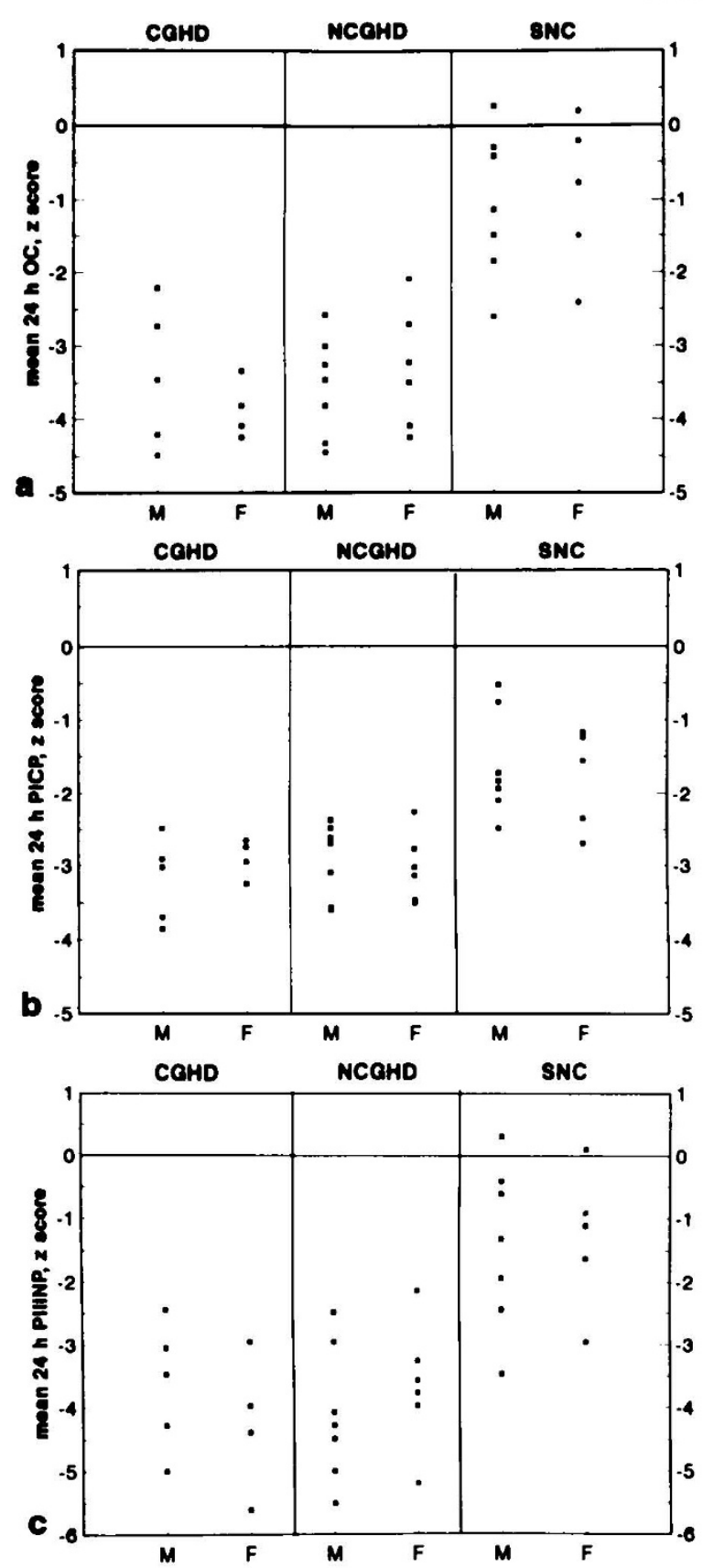

Fig. 2. Mean 24-h serum OC (a), PICP $(b)$, and PIIINP (c) concentrations in the subjects. Data are expressed as $z$ scores in respect to control SD for males $(M)$ and females $(F)$.

compared with those of the controls, significantly lower values for each parameter at all the time points of measurement were found (Fig. 3). In SNC, significantly lower smoothed 24-h OC mean data were demonstrated at all time points of measurement only during daytime, whereas nocturnal smoothed data were similar to those observed in controls (Fig. 3). In this group of patients, smoothed 24-h PICP and PIIINP mean data resulted in significantly lower values at all time points of measurement in comparison with mean data found in controls (Fig. 3).

In all subjects, diurnal 12-h MGHC was significantly lower than nocturnal 12-h MGHC; all three groups of patients had significantly reduced MGHC for both daytime and nighttime compared with controls (Table 2). Nocturnal 12-h OC and PICP mean data were significantly higher than diurnal $12-\mathrm{h}$ mean data in either patients or controls, but to a lesser extent for PICP (Table 2). Nocturnal 12-h PIIINP mean data were similar to diurnal 12-h PIIINP mean data in either patients or controls
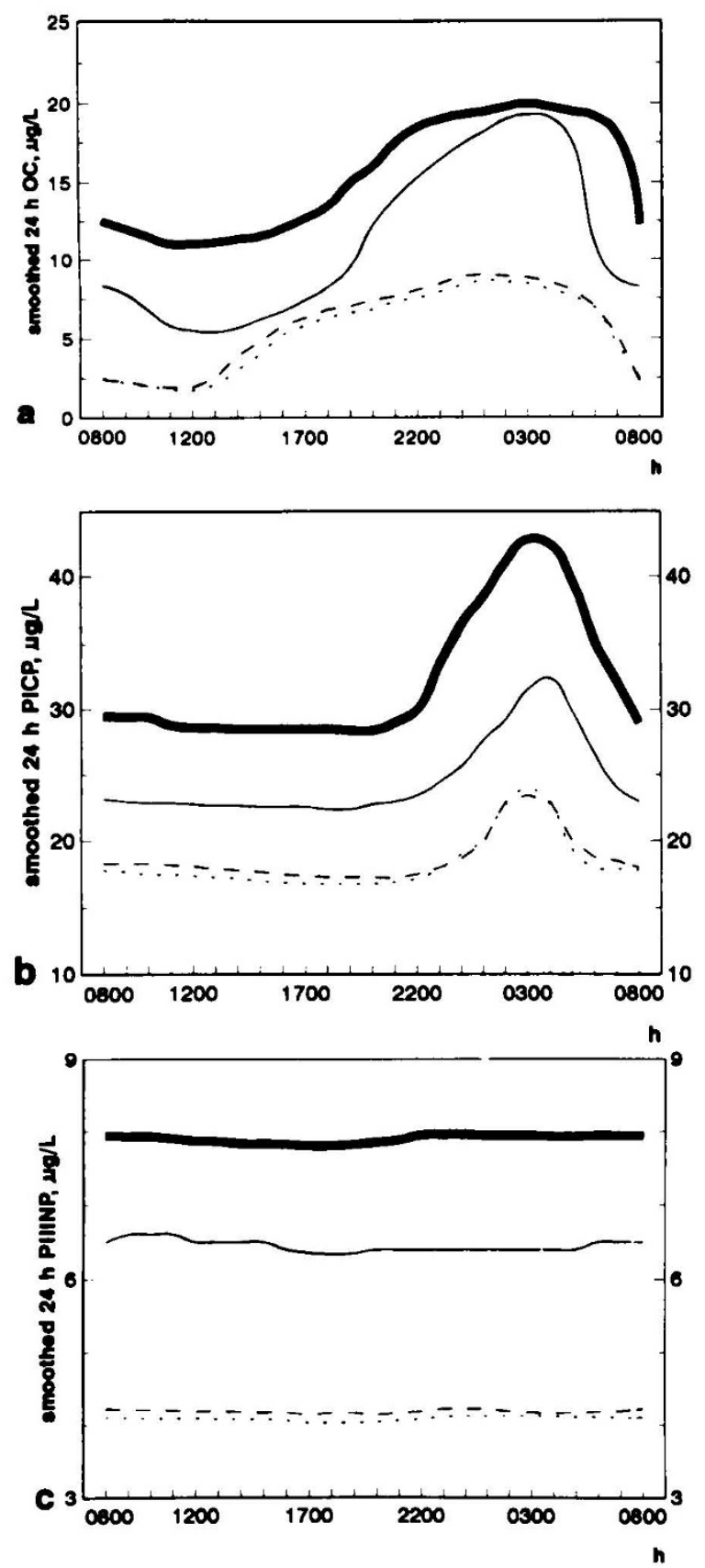

Fig. 3. Pattern of smoothed 24-h OC (a), PICP (b), and PIIINP (c) mean data of the subjects. CGHD: dotted line, NCGHD: broken line, SNC: solid fine line; controls: solid thick line. CGHD and NCGHD children $v s$ controls: $p<0.001$ at all the time points of measurement for OC, PICP, and PIIINP. SNC vs controls: for OC, $p<0.01$ from 0600 to $1900 \mathrm{~h}$ and $p=$ NS from 2000 to $0500 \mathrm{~h}$; for PICP, $p<0.01$ from 0800 to $2300 \mathrm{~h}$ and $p<0.001$ from 0000 to $0700 \mathrm{~h}$; for PIIINP, $p<0.001$ at all the time points of measurement.

(Table 2). In CGHD and NCGHD children, both nocturnal and diurnal 12-h mean data for OC, PICP, and PIIINP were significantly lower in respect to those of SNC and controls (Table 2). In SNC, only diurnal 12-h OC mean data were significantly lower in comparison with control data (Table 2), whereas 12-h PICP and PIIINP mean data were significantly lower than control data during both daytime and nighttime (Table 2).

Circadian pattern and daytime and nighttime mean data of GH, OC, PICP, and PIIINP did not vary with age, sex, and seasons (data not shown).

No relationship was found between 24-h OC mean data and 24-h MGHC, and between each time point of measurement of 
Table 2. Nocturnal 12-h and diurnal 12-h mean data of GH, OC, PICP and PIIINP in subjects*

\begin{tabular}{|c|c|c|c|c|}
\hline & Nocturnal $12 \mathrm{~h}$ & Diurnal $12 \mathrm{~h}$ & $\Delta \% \dagger$ & $p \dagger$ \\
\hline \multicolumn{5}{|l|}{ CGHD } \\
\hline $\mathrm{GH}(\mu \mathrm{g} / \mathrm{L})$ & $2.0 \pm 0.4 \ddagger \S$ & $1.3 \pm 0.5 \ddagger \S$ & 34.2 & $<0.01$ \\
\hline $\mathrm{OC}(\mu \mathrm{g} / \mathrm{L})$ & $7.4 \pm 1.1 \ddagger \S$ & $3.5 \pm 1.7 \ddagger \S$ & 52.4 & $<0.001$ \\
\hline $\operatorname{PICP}(\mu \mathrm{g} / \mathrm{L})$ & $19.6 \pm 2.4 \ddagger \S$ & $17.2 \pm 2.1 \ddagger \S$ & 12.4 & $<0.02$ \\
\hline PIIINP $(\mu \mathrm{g} / \mathrm{L})$ & $4.1 \pm 1.0 \ddagger \S$ & $4.1 \pm 0.9 \ddagger \S$ & 0.7 & NS \\
\hline \multicolumn{5}{|l|}{ NCGHD } \\
\hline $\mathrm{GH}(\mu \mathrm{g} / \mathrm{L})$ & $1.9 \pm 0.4 \ddagger$ & $1.5 \pm 0.5 \ddagger$ & 22.6 & $<0.02$ \\
\hline$O C(\mu \mathrm{g} / \mathrm{L})$ & $7.9 \pm 1.1 \ddagger$ & $3.9 \pm 1.3 \ddagger$ & 49.9 & $<0.001$ \\
\hline $\operatorname{PICP}(\mu \mathrm{g} / \mathrm{L})$ & $19.8 \pm 2.2 \ddagger$ & $17.8 \pm 2.3 \ddagger$ & 10.2 & $<0.02$ \\
\hline PIIINP $(\mu \mathrm{g} / \mathrm{L})$ & $4.1 \pm 1.0 \ddagger$ & $4.1 \pm 0.9 \ddagger$ & 0.5 & NS \\
\hline \multicolumn{5}{|l|}{ SNC } \\
\hline $\mathrm{GH}(\mu \mathrm{g} / \mathrm{L})$ & $5.8 \pm 1.1 \| \rrbracket$ & $3.8 \pm 1.2 \|$ ๆ & 34.5 & $<0.001$ \\
\hline $\mathrm{OC}(\mu \mathrm{g} / \mathrm{L})$ & $16.9 \pm 3.29 * *$ & $6.9 \pm 1.3 \ddagger \pi$ & 59.0 & $<0.001$ \\
\hline $\operatorname{PICP}(\mu \mathrm{g} / \mathrm{L})$ & $27.0 \pm 3.0 \| \rrbracket$ & $22.7 \pm 2.1 \ddagger \pi$ & 15.8 & $<0.001$ \\
\hline PIIINP $(\mu \mathrm{g} / \mathrm{L})$ & $6.7 \pm 0.9 \pi+\dagger$ & $6.45 \pm 1.09+\dagger$ & 3.4 & NS \\
\hline \multicolumn{5}{|l|}{ Controls } \\
\hline $\mathrm{GH}(\mu \mathrm{g} / \mathrm{L})$ & $8.0 \pm 1.0$ & $5.9 \pm 0.9$ & 25.9 & $<0.02$ \\
\hline$O C(\mu \mathrm{g} / \mathrm{L})$ & $19.4 \pm 2.1$ & $12.5 \pm 1.7$ & 35.7 & $<0.001$ \\
\hline $\operatorname{PICP}(\mu \mathrm{g} / \mathrm{L})$ & $34.5 \pm 4.6$ & $28.7 \pm 3.5$ & 16.6 & $<0.001$ \\
\hline PIIINP $(\mu \mathrm{g} / \mathrm{L})$ & $7.9 \pm 1.1$ & $7.8 \pm 1.0$ & 1.6 & NS \\
\hline
\end{tabular}

$*$ Values are mean $\pm \mathrm{SD}$.

+ Between diurnal and nocturnal mean data.

$\ddagger p<0.001$ vs controls.

$\S p=\mathrm{NS}$ vs NCGHD.

$\| p<0.01$ vs controls.

$p<0.001$ vs CGHD and NCGHD children.

$* * p=\mathrm{NS} v s$ controls.

$\dagger \dagger p<0.02$ vs controls.

serum $\mathrm{OC}$ and $\mathrm{GH}$ concentrations during $24 \mathrm{~h}$ (data not shown). On the contrary, 24-h PICP and PIIINP mean data were positively related to 24-h MGHC (Fig. 4), as was 12-h PICP and PIIINP mean data to 12-h MGHC during both daytime and nighttime (daytime PICP versus daytime MGHC: $r=0.63, p<$ 0.005 ; nighttime PICP versus nighttime MGHC: $r=0.75, p<$ 0.005; daytime PIIINP versus daytime MGHC: $r=0.57, p<$ 0.005 ; and nighttime PIIINP versus nighttime MGHC: $r=0.61$, $p<0.005$ ). Moreover, 24-h PICP and 24-h PIIINP mean data were positively related to growth velocity (Fig. 5), whereas 24-h OC mean data were not (data not shown).

\section{DISCUSSION}

During childhood, serum OC, PICP, and PIIINP concentrations vary with age, with patterns resembling growth velocity curves; higher values are observed during the first $2 \mathrm{y}$ of life and at puberty, and the increase occurs earlier in girls than in boys $(8,11-13,38,39)$. Thus, OC, PICP, and PIIINP concentrations in serum may have clinical usefulness as biochemical markers of growth-related changes during childhood and adolescence. In addition, OC and PICP also reflect bone formation, being osteoblast products $(4,9-12,15,16)$, whereas PIIINP may give information about the activity of connective tissue during growth $(8,9,11)$, because type III collagen accounts for $10-50 \%$ of total body collagen (6).

Our data confirm the presence of circadian $\mathrm{OC}$ rhythm in prepubertal, normal-statured, healthy children, as previously reported in young adults $(24,26,27)$ and children $(25)$, in GHdeficient patients $(28)$, and in SNC $(29,30)$. In contrast to baseline serum $O C$ concentrations, which showed an intraindividual coefficient of variation of $9-18 \%$ (27), circadian OC rhythm is remarkably constant in normal subjects $(26,27)$, as well as in CGHD and NCGHD children and in SNC tested. So, it may be more appropriate to assess osteoblast activity by measuring circadian OC rhythm than by measuring serum OC concentrations in single blood samples, even though this method
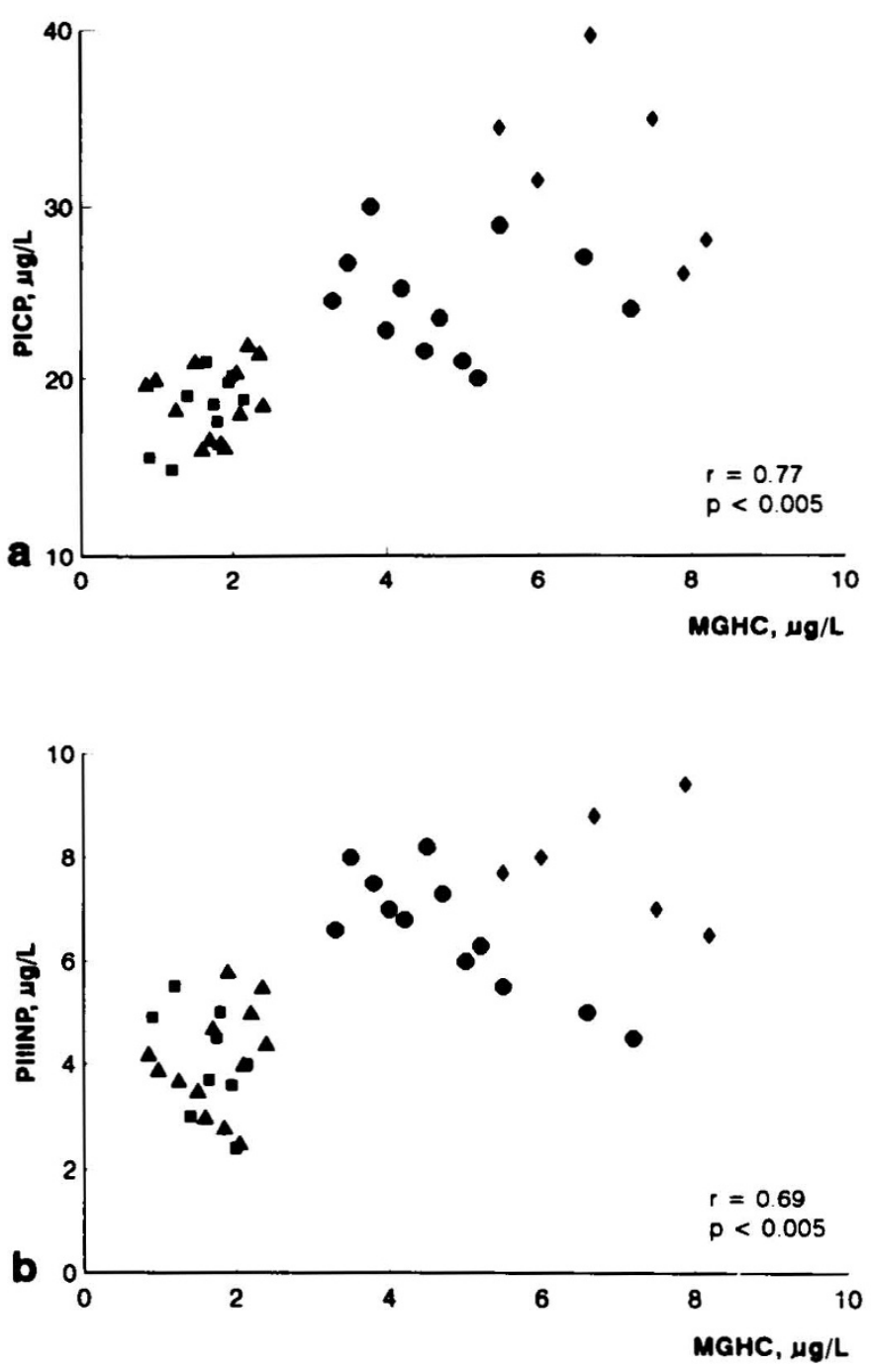

Fig. 4. Relationships between 24-h PICP mean data and 24-h MGHC (a), and between 24-h PIIINP mean data and 24-h MGHC (b). CGHD; $\triangle$, NCGHD; $\bullet$, SNC: $\bullet$, controls.

is more invasive and difficult to perform in large series of patients. In agreement with the data of Hassager $e t$ al. (32) obtained in premenopausal women, we demonstrated a circadian PICP rhythm with higher values during the night also in prepubertal, normal-statured, healthy children, as well as in GH-deficient children and in SNC. We did not find any 24-h variation in serum PIIINP concentrations in all examined subjects, in agreement with previous data obtained in GH-deficient children (8) and in SNC (33).

In CGHD and NCGHD children, the reduction in 24-h mean data and in smoothed 24-h mean data of OC probably reflects reduced bone turnover and decreased bone formation, as is also supported by the findings of low baseline serum $O C$ levels in these patients (14-18). In GH-deficient children, GH treatment at a dosage of 4 and $6 \mathrm{IU} / \mathrm{d}$ normalized the abnormal nighttime OC pattern, suggesting that circadian $\mathrm{OC}$ rhythm, which reflects circadian rhythmicity of osteoblast activity, could be related to circadian GH spontaneous secretion (28). Moreover, in GHdeficient children, baseline serum OC levels increased within 4 to $9 \mathrm{~h}$ after intramuscular $\mathrm{GH}$ administration, suggesting a direct effect of GH on OC levels independent of IGF-I increase (40). Our own previous data in CGHD and NCGHD children (17) did not confirm the rapid OC increase after $\mathrm{GH}$ administration, and the present study did not show any relationship between circadian OC rhythm and GH release evaluated by $24-\mathrm{h}$ MGHC, diurnal MGHC, nocturnal MGHC, and number of pulses greater 

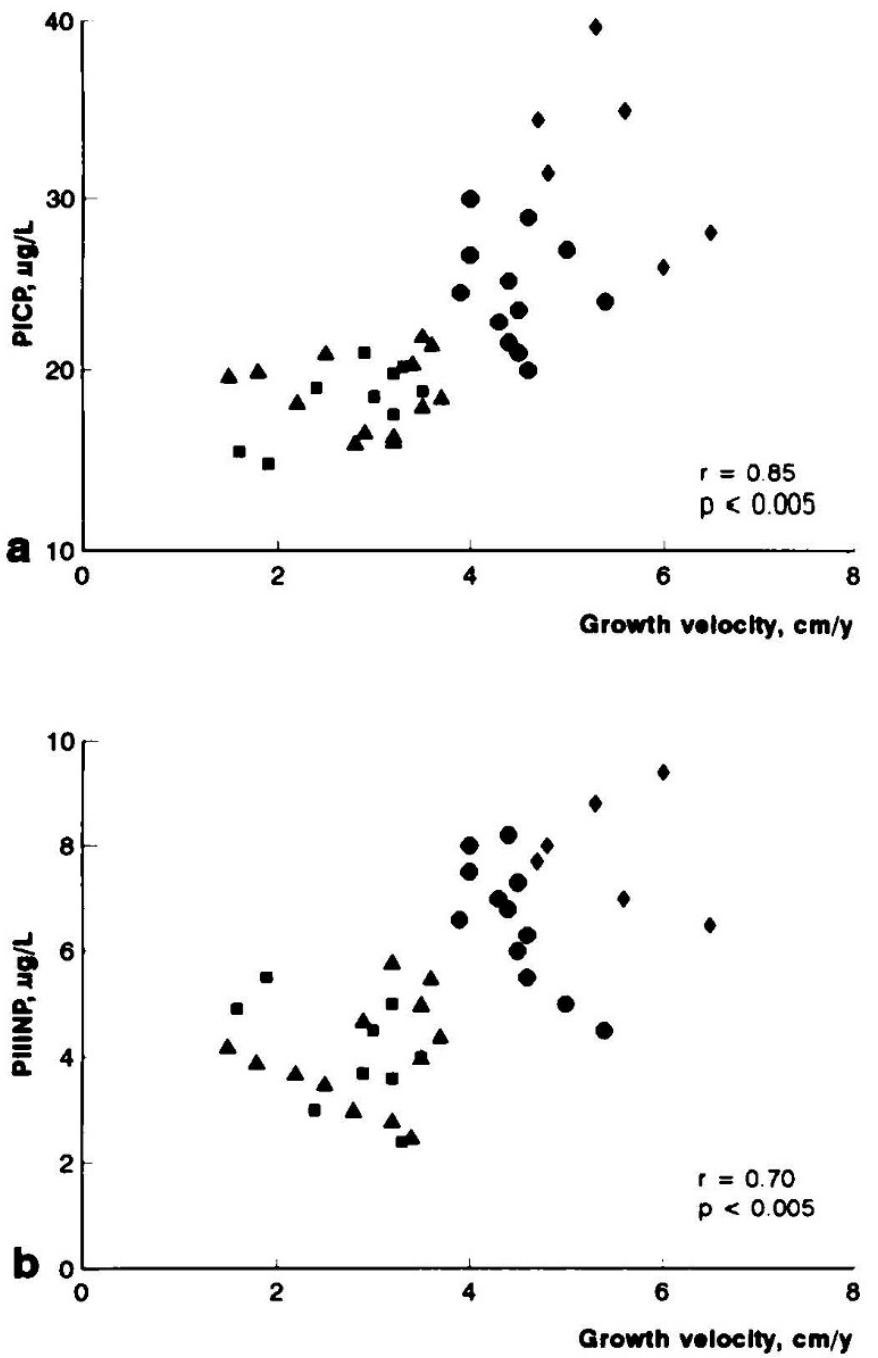

Fig. 5. Relationships between 24-h PICP mean data and growth velocity $(a)$, and between 24-h PIIINP mean data and growth velocity

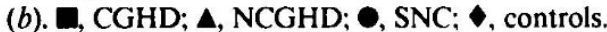

than $5 \mu \mathrm{g} / \mathrm{L}$ during $24 \mathrm{~h}$, confirming other reports $(27,28,41)$. Either 24-h mean data or smoothed 24-h mean data of OC may be used to assess some effects of GH deficiency and GH treatment on bone metabolism. Other factors, such as ionized calcium, PTH, and cortisol, may be involved in circadian OC fluctuations $(42,43)$. In CGHD and NCGHD children, reduced 24-h mean data and smoothed 24-h mean data of PICP and PIIINP revealed that poor growth is associated with decreased type I and type III collagen synthesis, confirming baseline measurement of serum PICP $(11,17,19)$ and PIIINP $(8,11,20)$. The relationships between 24-h PICP and PIIINP mean data and 24-h MGHC and growth velocity suggest that either spontaneous $\mathrm{GH}$ secretion or growth velocity may affect serum PICP and PIIINP concentrations. These data agree with the results of Trivedi et al. $(8,11)$, which showed a similar correlation between both baseline serum PICP and PIIINP levels and growth velocity, and between 24-h spontaneous GH secretion evaluated by area under the curve and serum PIIINP. So, the measurement of 24-h PICP and PIIINP mean data and circadian PICP and PIIINP rhythm may provide additional information to monitor growth rates in CGHD and NCGHD children and in SNC, even though an overlap in 24-h PICP and PIIINP mean data was found between CGHD and NCGHD children and SNC and between SNC and controls. In contrast to the data of Trivedi et al. $(8,11)$, no overlap in 24-h PICP and PIIINP mean data was observed between patients with $\mathrm{GH}$ deficiency and controls. The discrepancy between these data may be related to the major degree of growth failure and reduced growth velocity of our own patients compared with those examined by Trivedi et al. $(8,11)$.

In SNC, mean 24-h serum OC concentrations were not different from those of controls, but OC values during diurnal hours were reduced compared with the diurnal values in the controls. These data might reflect reduced bone formation during daytime, suggesting an impairment in osteoblast cyclic activity to produce OC.

Recent reports showed that OC is released from osteoblast into bone matrix and blood after cleavage of a 26-residue propeptide known as pro-OC; this propeptide circulates in lower levels than does the intact OC molecule, because most of the propeptide is catabolized within the osteoblasts and a relatively small amount is released into circulation $(16,44)$. Serum pro-OC concentration seems to be more specific than intact $O C$ as a marker of bone formation because it is not incorporated in bone matrix during bone formation (16). The lower serum OC level that occurs during diurnal hours in our SNC could result from a reduced osteoblast production of intact OC or from an increased osteoblast catabolism of pro-OC. We are not able to verify these suppositions because we measured serum OC concentrations by using rabbit antibovine $O C$ antibody that recognizes a major epitope near the carboxyterminal portion of the molecule detecting both intact $\mathrm{OC}$ and carboxyterminal fragments of the molecule $(45,46)$; therefore, the method we used is unable to detect intact OC molecules alone or measure pro-OC peptide. Alternatively, the apparent normality of nighttime OC data in SNC could be related to increased bone resorption during nocturnal hours, because a fraction of immunoreactive $O C$ fragments are released into blood during bone resorption by osteoclast, and the method to measure serum OC concentrations that we used also detects these fragments $(16,44-46)$. In contrast to our results, Markowitz et al. (30) in four children with idiopathic short stature demonstrated a reduced OC pattern during either daytime or nighttime using the same RIA we used. Differences in selection criteria of the patients may explain these conflicting data.

In contrast to OC, 24-h mean data and circadian pattern of PICP and PIIINP were significantly lower in SNC than in controls for both nighttime and daytime, suggesting that poor growth affects serum 24-h PICP and PIIINP concentrations, even if in the presence of normal GH secretion. The differences between the pattern of OC and that of PICP in SNC may be related to the possibility that these biochemical markers reflect different osteoblast functions, even though 24-h PICP mean data are likely influenced by soft connective tissue sources in addition to the organic bone matrix activity. Although 24-h PICP and PIIINP mean data were significantly higher in SNC in comparison with CGHD and NCGHD children, measurement of 24-h PICP and PIIINP mean data alone had no diagnostic value because we found a considerable overlap between these groups of patients and between SNC and controls. GH treatment was able to increase circadian PIIINP concentrations in children with SNC, but to a lesser extent than reported in GH-deficient children (33). So, 24-h PICP and PIIINP concentrations before and during GH treatment may be helpful in monitoring somatic growth in SNC.

In conclusion, our study demonstrates that 24-h PICP and PIIINP concentrations seem to be GH dependent in CGHD and NCGHD children, but this was less evident in SNC who showed normal GH secretion on the basis of the cutoff limits we used. The 24-h PICP and PIIINP levels were correlated to spontaneous $\mathrm{GH}$ secretion and growth velocity, whereas OC levels were not. Circadian variations in serum OC, PICP, and PIIINP concentrations in CGHD and NCGHD children and in SNC provide additional tools to assess bone formation (OC and PICP) and somatic growth (PICP and PIINP) in respect to the measurement of baseline values. Future studies are necessary to know for certain the diagnostic and prognostic usefulness of the circadian evaluation of these biochemical markers in children with short stature related or not to GH deficiency. 


\section{REFERENCES}

1. Price PA, Nishimoto SK 1980 RIA for the vitamin K-dependent protein of bone and its discovery in plasma. Proc Natl Acad Sci USA 77:2234-2238

2. Saggese G, Baroncelli GI, Bertelloni S, Buggiani B 1989 Livelli normali di osteocalcina in età pediatrica. Comparazione con la mineralizzazione ossea e con le variazioni fisiologiche dei livelli di 1,25-diidrossivitamina D. Riv Ital Pediatr 15:109-112

3. Delmas PD, Malaval L, Arlot ME. Meunier PJ 1985 Serum bone Gla-protein compared to bone hystomorphometry in endocrine diseases. Bone 6:339341

4. Parfitt AM, Simon LS, Villanueva AR, Krane SM 1987 Procollagen type carboxy-terminal extension peptide in serum as a marker of collagen biosynthesis in bone. Correlation with iliac bone formation rates and comparison with total alkaline phosphatase. J Bone Miner Res 2:427-436

5. Risteli J, Risteli L 1989 Growth and collagen. Curr Med Lit-Growth and Growth Factors 4:159-164

6. Prockop DJ, Kivirikko KJI. Tuderman L, Guzman NA 1979 The biosynthesis of collagen and its disorders. N Engl J Med 301:13-23

7. Melkko J. Niemi S, Risteli L. Risteli J 1990 Radioimmunoassay of the carboxyterminal propeptide of human type 1 procollagen. Clin Chem 36:1328-1332

8. Trivedi P, Hindmarsh PC, Risteli J, Risteli L, Mowat AP, Brook CGD 1989 Growth velocity, growth hormone therapy, and serum concentrations of the amino-terminal propeptide of type III procollagen. J Pediatr 114:225-230

9. Graham MF 1989 The use of serum levels of procollagen propeptides to predict growth velocity. J Pediatr Gastroenterol Nutr 2:143-145

10. Deftos LJ 1991 Bone protein and peptide assays in the diagnosis and management of skeletal disease. Clin Chem 37:1143-1148

11. Trivedi P, Risteli J, Risteli L, Hindmarsh PC, Brook CGD, Mowat AP 1991 Serum concentrations of the type I and III procollagen propeptides as biochemical markers of growth velocity in healthy infants and children and in children with growth disorders. Pediatr Res 30:276-280

12. Johansen JS, Giwercman A, Hartwell D. Nielsen CT. Price PA, Christiansen C, Skakkebaek NE 1988 Serum bone Gla-protein as a marker of bone growth in children and adolescents: correlation with age, height, serum insulin-like growth factor I, and serum testosterone. J Clin Endocrinol Metab 67:273278

13. Saggese G, Bertelloni S, Baroncelli GI. Di Nero G 1992 Serum levels of carboxyterminal propeptide of type I procollagen in healthy children from Ist year of life to adulthood and in metabolic bone diseases. Eur J Pediat 151:764-768

14. Delmas PD, Chatelain P, Malaval L. Bonne G 1986 Serum bone Gla-protein in growth hormone-deficient children. J Bone Miner Res 1:333-338

15. Johansen JS, Jensen SB, Riis BJ, Rasmussen L, Zachman M, Christiansen C 1990 Serum bone Gla-protein: a potential marker of growth hormone (GH) deficiency and the response to GH therapy. J Clin Endocrinol Metab 71:122126

16. Kanzaki S, Hosoda K. Moriwake T, Tanaka H, Kubo T. Inoue M, Higuchi J, Yamaji T, Seino Y 1992 Serum propeptide and intact molecular osteocalcin in normal children and children with growth hormone $(\mathrm{GH})$ deficiency: a potential marker of bone growth and response to $\mathrm{GH}$ therapy. J Clin Endocrinol Metab 75:1104-1109

17. Saggese G, Baroncelli GI, Bertelloni S, Cinquanta L, Di Nero G 1993 Effects of long-term treatment with growth hormone on bone and mineral metab olism in children with growth hormone deficiency. J Pediatr 122:37-45

18. Sartorio A, Conti A. Guzzaloni G, Faglia G 1991 Serum osteocalcin levels in patients with $\mathrm{GH}$ deficiency before and during $\mathrm{GH}$ treatment. Acta Paediat Scand 80:100-102

19. Carey DE, Goldberg B, Ratzan SK, Rubin KR. Rowe DW 1984 Radioimmunoassay for type 1 procollagen in growth hormone-deficient children before and during treatment with growth hormone. Pediatr Res 19:8-11

20. Danne T. Gruters A. Schuppan D, Quantas N, Enders I, Weber B 1989 Relationship of procollagen type III propeptide-related antigens in serum to somatic growth in healthy children and patients with growth disorders. Pediatr 114:257-260

21. Danne T, Gruters A, Schnabel K, Burger W, L'Allemand D, Enders I, Helge H, Weber B 1988 Long-term monitoring of treatment with recombinan human growth hormone by serial determinations of type III procollagenrelated antigens in serum. Pediatr Res 23:167-171

22. Saggese G, Baroncelli GI. Bertelloni S. Carlotti C. Cinquanta L 1991 Livelli di osteocalcina e di 1,25-diidrossivitamina D nella bassa statura idiopatica. Riv Ital Pediatr 17:535-537

23. Colle M, Ruffie A. Ruedas E, Chebbo M 1987 L'ostéocalcine chez l'enfant de petite taille et ses variations nocturnes. Arch Fr Pediatr 44:839-841

24. Gundberg CM, Markowitz ME, Mizruchi M, Rosen JF 1985 Osteocalcin in human serum: a circadian rhythm. J Clin Endocrinol Metab 60:736-739

25. Saggese G, Bertelloni S, Baroncelli GI, Ghirri P 1986 Ritmo circadiano dell'osteocalcina nel bambino. Minerva Pediatr 38:1035-1037

26. Nielsen HK, Brixen K, Mosekilde L 1990 Diurnal rhythm and 24-hour integrated concentrations of serum osteocalcin in normals: influence of age. sex, season, and smoking habits. Calcif Tissue Int 47:284-290

27. Nielsen HK, Brixen K, Kassem M. Christensen SE, Mosekilde L 1991 Diurnal rhythm in serum osteocalcin: relation with sleep, growth hormone, and PTH (1-84). Calcif Tissue Int 49:373-377

28. Nielsen HK, Jorgensen JOL, Brixen K, Christiansen JS 1991 Serum osteocalcin and bone isoenzyme alkaline phosphatase in growth hormone-deficient patients: dose-response studies with biosynthetic human GH. Calcif Tissue Int 48:82-87

29. Sposito M, De Giorgi G, Palumbo R, Sabalich T, Castellucci G, Truffarelli F. Rufini S 1991 Variazioni notturne dell'osteocalcina in bambini affetti da ipostaturalità costituzionale. Pediatr Med Chir 13:271-274

30. Markowitz ME, Dimartino-Nardi J, Gasparini F, Fishman K, Rosen JF, Saenger P 1989 Effects of growth hormone therapy on circadian osteocalcin rhythms in idiopathic short stature. J Clin Endocrinol Metab 69:420-425

31. Piovesan A, Torta M. Raucci CA. Buniva T, Turbiglio F. Berruti A 199224 hour profile of serum bone Gla protein and carboxyterminal propeptide of type I procollagen in healthy subjects. J Endocrinol Invest 15(suppl 1):289(abstr)

32. Hassager C. Risteli J, Risteli L, Jensen SB, Christiansen C 1992 Diurnal variation in serum markers of type I collagen synthesis and degradation in healthy premenopausal women. J Bone Miner Res 7:1307-1311

33. Markowitz ME, Saenger PH, Gasparini FJ, Fishman KP 1989 24-hour procollagen III levels during growth hormone treatment of children with idiopathic short stature. Pediatr Res 25:88A(abstr)

34. Saggese G, Cesaretti G 1989 Criteria for recognition of the growth-inefficient child who may respond to treatment with growth hormone. Am J Dis Child 143:1287-1293

35. Tanner JM, Whitehouse RH, Takaishi M 1966 Standards from birth to maturity for height, weight, height velocity and weight velocity: British children-1965. Arch Dis Child 41:454-471, 613-634

36. Greulich WW. Pyle SI 1959 Radiographic Atlas of Skeletal Development of the Hand and Wrist, 2nd Ed. Stanford University Press, Stanford, CA

37. McNeil DR 1977 Interactive Data Analysis. Wiley, New York, pp 119-130

38. Delemarre-van de Waal HA, Martens F, Odnik RJH 1991 Type I procollagen levels in relation to growth, growth hormone, SmC and sex steroids throughout normal puberty. Hormone Res 35(suppl 2):41(abstr)

39. Hertel NT, Stoltenberg M, Muller J, Lorenzen I, Skakkebaek NE 1992 procollagen I and III in children and adolescents: correlation to linear growth and pubertal maturation. Hormone Res 37(suppl 4):57(abstr)

40. Bastian W, Castells S, Torrado C. Yasumura S, Smith S 1989 Changes in plasma osteocalcin and somatomedin-c in growth hormone deficiency after intramuscular injection of hGH. Pediatr Res 25:80A(abstr)

41. Ebeling PR, Butler PC. Eastell R, Rizza RA, Riggs BL 1991 The nocturnal increase in growth hormone is not the cause of the nocturnal increase in serum osteocalcin. J Clin Endocrinol Metab 73:368-372

42. Nielsen HK, Lurberg P, Brixen K, Mosekilde L 1991 Relations between diurnal variations in serum osteocalcin, cortisol, parathyroid hormone, and ionized calcium in normal individuals. Acta Endocrinol (Copenh) 124:391-398

43. Nielsen HK. Brixen K, Kassem M. Charles P. Mosekilde L 1992 Inhibition of the morning cortisol peak abolishes the expected morning decrease in serum osteocalcin in normal males: evidence of a controlling effect of serum cortisol on the circadian rhythm in serum osteocalcin. J Clin Endocrinol Metab 74:1410-1414

44. Hauschka PV, Lian JB, Cole DEC. Gundberg CM 1989 Osteocalcin and matrix Gla protein: vitamin K-dependent proteins in bone. Physiol Rev 69:990-1047

45. Taylor AK, Linkart SG, Mohan S, Baylink DJ 1988 Development of a new radioimmunoassay for human osteocalcin: evidence for a midmolecule epitope. Metabolism 37:872-877

46. Power MJ, Gosling JP. Fottrel PF 1989 Radioimmunoassay of osteocalcin with polyclonal and monoclonal antibodies. Clin Chem 35:1408-1415 